\title{
Silent Thecoma of Ovary - A Rare Case
}

\author{
Sakshi Sharad Duragkar ${ }^{1}$, Surekha Atul Tayade², Kiran Pralhadrao Dhurve³, Smriti Khandelwal ${ }^{4}$ \\ ${ }^{1}$ Department of Obstetrics and Gynaecology, Jawaharlal Nehru Medical College (JNMC), DMIMS, DU, \\ Sawangi Meghe, Wardha, Maharashtra, India. ${ }^{2}$ Department of Obstetrics and Gynaecology, Jawaharlal \\ Nehru Medical College (JNMC), DMIMS, DU, Sawangi Meghe, Wardha, Maharashtra, India. \\ ${ }^{3}$ Department of Obstetrics and Gynaecology, Jawaharlal Nehru Medical College (JNMC), DMIMS, DU, \\ Sawangi Meghe, Wardha, Maharashtra, India. ${ }^{4}$ Department of Obstetrics and Gynaecology, Jawaharlal \\ Nehru Medical College (JNMC), DMIMS, DU, Sawangi Meghe, Wardha, Maharashtra, India.
}

\section{INTRODUCTION}

Theca cell tumours are benign ovarian tumours. These tumours are of stromal origin. Most commonly they are seen in premenopausal and postmenopausal women. Usually they are asymptomatic and are found incidentally. Ovarian cancers can be of benign and malignant type. According to WHO classification, they are classified as epithelial, germ cell, sex cord stromal tumours and others. ${ }^{1}$ Among them epithelial ovarian cancer are most common, and the least common variety is of sex cord stromal tumours. About $1 \%$ of ovarian cancers are thecoma. ${ }^{2}$ These tumours are most commonly found in postmenopausal women however about $2 \%$ of stromal tumours occur in young girls. ${ }^{3}$ Theca cell tumours are also known as hormone producing tumours as they produce oestrogen hormone. Usually the patient presents with complaint of post-menopausal bleeding because of the oestrogen which is secreted by theca cell tumours. Imaging modalities (ultrasonography and CT scan) are of little help in differentiating thecoma from other types of ovarian tumours, because of radiological close resemblance to other tumours. ${ }^{4}$ Here we enlightened the symptomless presentation of such a huge thecoma which was diagnosed incidentally.

\section{PRESENTATION OF CASE}

A 53 years old, second para with 2 living children and post-menopausal since 7 years presented to OPD of a rural tertiary care centre with the chief complaint of acidity since few days. There was no significant medical, past or family history. On examination, vitals were normal. Cardiovascular and respiratory examination findings were normal. On abdominal examination, a large solitary abdominal mass around $20-22$ weeks size of gravid uterus was felt more towards left side of abdomen, which was heterogeneous in consistency, painless and mobile. Per speculum examination and per vaginal examination were normal. Patient was admitted.

\author{
Corresponding Author: \\ Dr. Surekha Atul Tayade, \\ Department of $O B G$, \\ JNMC, Sawangi, Meghe, \\ Wardha, Maharashtra, India. \\ E-mail: surobgy@gmail.com
}

DOI: $10.14260 / j e m d s / 2020 / 541$

How to Cite This Article: Duragkar SS, Tayade SA, Dhurve KP, et al. Silent thecoma of ovary - a rare case. J Evolution Med Dent Sci 2020;9(34):24902492, DOI: $10.14260 /$ jemds/2020/541

Submission 08-05-2020,

Peer Review 11-07-2020,

Acceptance 17-07-2020,

Published 24-08-2020.

Copyright (c) 2020 JEMDS. This is an open access article distributed under Creative Commons Attribution License [Attribution 4.0 International (CC BY 4.0)] 


\section{CLINICAL DIAGNOSIS}

Ca Ovary

\section{DISCUSSION OF MANAGEMENT}

Ultrasonography of abdomen and pelvis was done, suggesting a large solid cystic mass around $21 \times 11 \mathrm{cms}$ seen in the pelvis extends up to the lower abdomen which shows mild vascularity within. CT scan of the abdomen and pelvis suggesting a lower abdomino-pelvic, large well defined solid cum cystic lesion around $23 \times 14 \times 16$ cms.

It has cranial large cystic lesion with caudal heterogeneous enhancing solid component appearing as neoplastic ovarian tumour. Ovary was not visualized separately from mass. Subtle omental thickening noted. Visualized uterus small sized and appears normal. The tumour markers were within normal range except CA125 which was $139 \mathrm{U} / \mathrm{ml}$, moderately increased. Clinical suspicion of ovarian malignancy was made. With informed consent exploratory laparotomy was done. Intraoperatively a large abdominal mass around 23x14x16 cm found which was partially solid and partially cystic attached to uterus at left infundibulopelvic ligament. Omentum showed deposits. Around 200 cc of ascitic fluid was present which was collected and sent for cytology. Frozen section report of fresh specimen was sent, and report was suggestive of sex cord stromal tumour. Total abdominal hysterectomy along with bilateral salpingo-oophorectomy was done. Partial omentectomy was done. Final histopathology report was suggesting thecoma of left ovary, omentum and peritoneal fluid were free from malignancy. Post-operative period was uneventful and patient was discharged on day 9 .
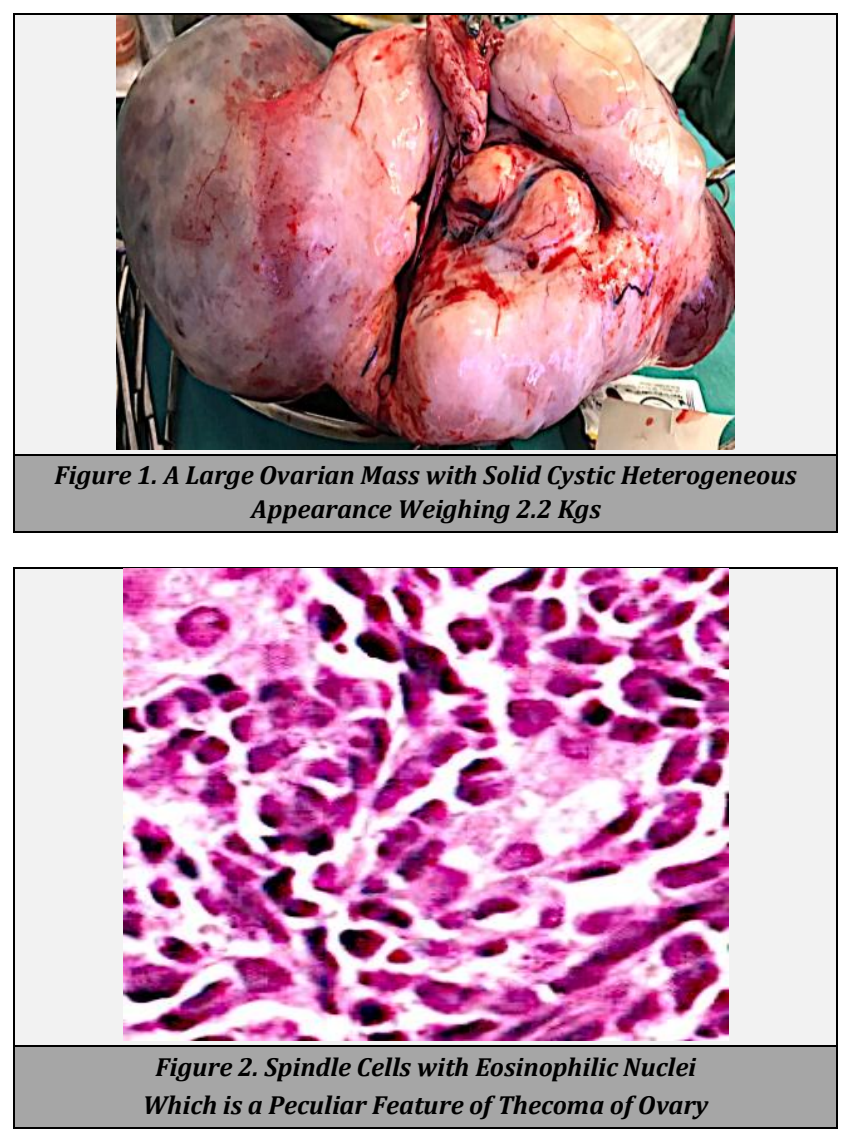

DISCUSSION

Sex Cord Stromal Tumours (SCST) are a rare type of ovarian neoplasm. Among them thecoma are the rarest one, contributing $1 \%$ of all ovarian neoplasm. ${ }^{5}$ As per revised WHO classification (2014) SCST are classified into pure stromal tumours, pure sex cord tumours, and mixed sex cord-stromal tumours ${ }^{6}$. Thecoma is included under pure stromal tumours of ovary. Ovarian SCSTs are derived from the coelomic epithelium and mesenchyma of the embryonic gonads. ${ }^{3}$ Theca cell tumour composed of lipid laden cells with fibroblast. ${ }^{7}$ Theca cell tumour is well known for its hormonal activity. Theca cell secrets oestrogen hence sometimes patient presents with symptoms related to hyperoestrogenaemia such as abnormal uterine bleeding, endometrial hyperplasia, endometrial cancer. ${ }^{8}$ In most of the cases thecoma presents as unilateral mass affecting both premenopausal and postmenopausal women ${ }^{9}$ (like in our case). Fibroma, one of the variants of SCST can present with ascites, right sided hydrothorax and benign ovarian mass which is known as Meigs's syndrome.10 In our case we accidently found the abdominal mass. Patient didn't have any complaints. Patient assumed that she was putting on weight and didn't felt any mass. In one study Chen and et $\mathrm{al},{ }^{8}$ concluded that thecoma and fibroma often occur in postmenopausal women with no obvious clinical symptoms. If mass is large patient may present to you with complaint of pain in abdomen and mass per abdomen. In our case despite the huge mass patient was asymptomatic. Sometimes radiographic imaging modalities specifically ultrasonography and CT scans are unable to differentiate between thecoma and other solid ovarian tumours. ${ }^{11}$ Clinically she was suspected to be a case of ovarian malignancy as the mass was huge, moderately raised CA125 value and CT scan showed neoplastic ovarian tumour but histopathology was suggestive of thecoma of ovary.

\section{CONCLUSIONS}

Thecoma is a rare benign tumour of ovary. There are certain symptoms by which it presents. Sometimes with a huge abdominal mass, patient can be asymptomatic. So, need of meticulous examination, keeping in mind the possibility of benign mass is necessary. Surgery is the mainstay treatment.

The comas account for less than $1 \%$ of all ovarian tumours but are considered the most common form of functioning ovarian tumours. They are more frequent in peri menopausal and postmenopausal women. The- comas are rarely malignant and are only occasionally associated with ascites or the Meigs' syndromes. They generally exhibit estrogenic changes, but virilising thecomas have been reported. They are seldom bilateral or calcified grossly thecomas are firm or rubbery in consistency and vary from white to yellow to orange in colour. Oedema may be present, but cyst formation is rare.

Histologically, the typical thecoma is composed of masses of oval or spindle-shaped cells with round nuclei and pale vacuolated lipid-laden cytoplasm separated by collagen forming spindle cells like those seen in fibromas. The luteinized thecoma additionally contains scattered is lands of round polyhedral cells representing theca lutein or stromal lutein cells. The microscopic features of fibromas and 
thecomas may merge imperceptibly so that terms such as fibrothecoma or thecofibroma are quite common. The sonographic appearance of ovary thecomas account for less than $1 \%$ of all ovarian tumours but are considered the most common form of functioning ovarian tumour.

They are more frequent in peri menopausal and postmenopausal women. The comas are rarely malignant and are only occasionally associated with ascites or the Meigs' syndrome. They generally exhibit estrogenic changes, but virilising the comas have been reported. They are seldom bilateral or calcified. Grossly thecomas are firm or rubbery in consistency and vary from white to yellow to orange in colour. Oedema may be present, but cyst formation is rare. Histologically, the typical thecoma is composed of masses of oval or spindle-shaped cells with round nuclei and pale vacuolated lipid-laden cytoplasm separated by collagen forming spindle cells like those seen in fibromas. The luteinized thecoma additionally contains scattered islands of round polyhedral cells representing theca lutein or stromal lutein cells.

Financial or Other Competing Interests: None.

\section{REFERENCES}

[1] Kaku T, Ogawa S, Kawano Y, et al. Histological classification of ovarian cancer. Medical Electron Microscopy 2003;36(1):9-17.

[2] Siekierska-Hellmann M, Sworczak K, Babińska A, et al.
Ovarian thecoma with androgenic manifestations in a postmenopausal woman. Gynecological Endocrinology 2006;22(7):405-8.

[3] Heo SH, Kim JW, Shin SS, et al. Review of ovarian tumours in children and adolescents: radiologic-pathologic correlation. Radiographics 2014;34(7):2039-55.

[4] Takemori M, Nishimura R, Hasegawa K. Ovarian thecoma with ascites and high serum levels of CA125. Archives of Gynecology and Obstetrics 2000;264(1):42-4.

[5] Obeidat RA, Aleshawi AJ, Obeidat HA, et al. A rare presentation of ovarian fibrothecoma in a middle age female: case report. Int J Womens Health 2019;11:149-52.

[6] Roth LM. Recent advances in the pathology and classification of ovarian sex cord-stromal tumours. International Journal of Gynecological Pathology 2006;25(3):199-215

[7] Kulkarni YSS, Kakade AS, Singh BA. A rare case of ovarian thecoma in a postmenopausal woman. Int J Reprod Contraception, Obstet Gynecol 2014;3(1):242-4.

[8] Chen H, Liu Y, Shen LF, et al. Ovarian thecoma-fibroma groups: clinical and sonographic features with pathological comparison. Journal of Ovarian Research 2016;9(1):81.

[9] Chechia A, Attia L, Ben TR, et al. Incidence, clinical analysis and management of ovarian fibromas and fibrothecomas. Am J Obstet Gynecol 2008;199(5):473.e1-.e4.

[10] Jung SE, Rha SE, Lee JM, et al. CT and MRI findings of sex cord-stromal tumour of the ovary. American Journal of Roentgenology 2005;185(1):207-15.

[11] Athey PA, Malone RS. Sonography of ovarian fibromas/thecomas. J Ultrasound Med 1987;6(8):431-6. 